\title{
PERBANDINGAN KINERJA MEMBRAN KERAMIK BUATAN DENGAN MEMBRAN KERAMIK PABRIKASI PADA PENJERNIHAN AIR SUNGAI MUSI
}

\author{
Husnah \\ Dosen PNSD dpk Program Studi Teknik Kimia \\ Universitas PGRI palembang \\ e-mail: husnahpgri2gmail.com
}

\begin{abstract}
ABSTRAK
Membran yang umum digunakan dalam pengolahan air permukaan adalah membran keramik. Dalam penelitian ini digunakan dua jenis membran, yaitu membran buatan dan membran pabrikasi. Membran buatan merupakan hasil buatan manual dengan bahan dasar tanah liat, sedangkan Membran pabrikasi adalah membran keramik yang diproduksi oleh indutri pengolahan air. Proses Pengolahan ini bertujuan untuk memperbaiki kualitas air Sungai Musi. Proses filtrasi dilakukan dengan tekanan 32 dan 36 psi. Waktu pengambilan permeate dilakukan pada 15, 30, 45 dan 60 menit. Parameter yang diamati pada proses filtrasi ini adalah Fluks.
\end{abstract}

Kata kunci : Membran Keramik Buatan, Membran Keramik Pabrikasi, Filtrasi dan Fluks.

\section{PENDAHULUAN}

Kondisi Sungai Musi, saat ini telah masuk dalam kategori tercemar berat. Bahkan bisa dibilang memprihatinkan. Kondisi pencemarannya sudah masuk kategori berat berdasarkan hasil pantauan yang dilakukan oleh Dinas Lingkungan Hidup dan Pertanahan (LHP) Provinsi Sumsel sepanjang 2016. Tabel dibawah ini memperlihatkan hasil pantauan Dinas LHP di beberapa Sungai di Kota Palembang.

Tabel 1. Nilai Status Mutu Air Sungai pada Titik pantau di Kota Palembang Tahun 2016

\begin{tabular}{|l|l|c|}
\hline \multicolumn{1}{|c|}{$\begin{array}{c}\text { Lokasi } \\
\text { Pemantauan }\end{array}$} & \multicolumn{1}{|c|}{$\begin{array}{c}\text { Nama } \\
\text { Sungai }\end{array}$} & $\begin{array}{c}\text { Status } \\
\text { Mutu Air }\end{array}$ \\
\hline Pulokerto & Musi & Buruk \\
\hline Muara Keramasan & Keramasan & Sedang \\
\hline Intake PDAM & Musi & Buruk \\
\hline Kertapati & Ogan & Sedang \\
\hline Jembatan Ampera & Musi & Buruk \\
\hline Plaju/Sei Gerong & Komering & Buruk \\
\hline \multicolumn{2}{|l}{} \\
\hline
\end{tabular}

(Sumber Dinas Lingkungan Hidup dan Pertanahan Provinsi Sumsel)

Sungai Musi, berada di bagian yang tercemar berat. Ada tiga titik pantau di sepanjang Sungai Musi di kawasan Kota Palembang. Yakni kawasan Pulokerto (Gandus), kawasan Jembatan Ampera, dan Borang. Di ketiga titik pantau itu, jika dibiarkan kondisinya bisa mengkhawatirkan. 
Untuk industri yang berada di tepi Sungai Musi, sebagian besar telah memiliki pengolahan limbah yang sesuai peraturan yang berlaku. Karenanya, pencemaran saat ini didominasi limbah domestik yang berasal dari masyarakat.

Pencemaran Sungai Musi ini sangat mengkhawatirkan karena sungai ini masih menjadi sumber utama untuk memenuhi kebutuhan air, bahkan banyak masyarakat sekitar memanfaatkan sungai Musi untuk keperluan sehari-hari. Misalnya memasak, mencuci, mandi, bahkan buang air besar dan kecil pun disungai ini. Dan perusahaan daerah air minum (PDAM) juga memanfaatkan air dari sungai Musi ini sebagai bahan baku untuk memenuhi kebutuhan air bersih bagi masyarakat.

\section{TINJAUAN PUSTAKA}

Sumber-sumber air dapat digolongkan menjadi (Sutrisno, 2004) :

1. Air laut

Air laut mempunyai sifat resin karena mengandung garam $\mathrm{NaCl}$. Kadar garam dalam air laut mencapai $\pm 3 \%$.

2. Air permukaan

Air permukaan adalah air yang mendapat pengotoran selama pengalirannya misalnya oleh lumpur, limbah, rumah tangga dan limbah industri. Air permukaan terbagi menjadi air sungai dan air rawa/ danau. Air permukaan umumnya banyak dipergunakan sebagai bahan baku dalam memenuhi kebutuhan hidup. Karena itu air permukaan ini harus mendapat perhatian penting dalam pengelolaannya agar sumber air permukaan ini dapat memenuhi kebutuhan hidup manusia dengan layak.

3. Air atmosfer

Air atmosfer adalah air yang dalam keadaan murni sangat bersih tetapi karena adanya pengotoran udara yang disebabkan oleh industri-industri maka secara kualitas belum memenuhi standar baku mutu air karena masih banyak mengandung zat-zat tersuspensi. Air atmosfer termasuk dalam air tunak, contohnya air hujan atau air salju.

4. Air tanah

Air tanah secara kualitas cukup baik, karena secara alamiah telah tersaring secara fisik/bakteriologis oleh lapisan-lapisan tanah. Tetapi air tanah ini masih mengandung garamgaram mineral. Air tanah terbagi atas 3 (tiga) jenis yaitu :
[1] Air tanah dangkal
[2] Mata air
[3] Air tanah dalam

Sungai Musi sebagai salah satu sumber air permukaan yang menjadi salah satu Sungai Musi sebagai ikon kota Palembang itu ternyata tercemar limbah yang didominasi limbah rumah tangga, dan sisanya limbah industri. Data yang disampaikan Kepala Badan Lingkungan Hidup (BLH) Sumsel menyebutkan, sekitar 70 persen air Sungai Musi tercemar limbah rumah tangga, sedangkan sisanya 30 persen tercemar limbah perusahaan atau industri.

Tingkat pencemaran di Sungai Musi meningkat akibat aktivitas industri dan limbah rumah tangga. Unsur pencemar tertinggi, seperti fenol, besi, dan fosfat, sudah melebihi nilai ambang batas sehingga berpotensi mengancam organisme sungai. Sebagian besar limbah rumah tangga tersebut masuk Sungai Musi melalui aliran anak sungainya yang bermuara ke Sungai Musi. 
Beberapa anak sungai di Kota Palembang berisiko tercemar tersebut di antaranya, yaitu Sungai Bendung, Sungai Aur, Sungai Sekanak, Sungai Buah, Sungai Ogan, Sungai Demang Jambul, Sungai Sintren, Sungai Jeurju, dan Sungai Rendang. Selain menimbulkan bau tidak sedap, sampah mengambang di aliran anak sungai ini. Sampah plastik, kayu, daun-daun, dan lainnya hanyut mengikuti aliran menuju Sungai Musi. Meskipun warna airnya hitam pekat masih sering digunakan sebagian warga terutama anak-anak untuk mandi.

Limbah adalah suatu benda atau zat yang dapat mengandung berbagai bahan yang membahayakan kehidupan manusia, hewan, serta makhluk hidup lainnya. Banyak limbah dihasilkan dari aktivitas manusia, termasuk industri dan kegiatan rumah tangga. Masuknya limbah rumah tangga dan industri ke dalam suatu lingkungan menyebabkan pencemaran atau polusi dilingkungan tersebut. Jenis pencemaran dibedakan antara lain :

* Berdasarkan tempat terjadinya

[1] pencemaran udara

[2] pencemaran air

[3] pencemaran tanah

* Berdasarkan bahan pencemarnya

[1] Pencemaran kimiawi

[2] Pencemaran biologi

[3] Pencemaran fisik

[4] Pencemaran suara

* Berdasarkan tingkat pencemaran

[1] Pencemaran ringan

[2] Pencemaran kronis

[3] Pencemaran akut

Sebagai upaya untuk mengatasi pencemaran air Sungai Musi ini telah banyak teknologi yang diupayakan agar air Sungai Musi layak sebagai air baku untuk memenuhi kebutuhan hidup manusia. Salah satu teknologi yang semakin berkembang adalah teknologi membran. Pemisahan dengan membran memiliki banyak keunggulan diantaranya pemisahan dengan membran tidak membutuhkan zat kimia tambahan dan juga kebutuhan energinya sangat minimum. Membran dapat bertindak sebagai filter yang sangat spesifik. Hanya molekul-molekul dengan ukuran tertentu saja yang bisa melewati membran sedangkan sisanya akan tertahan di permukaan membran. Selain keunggulankeunggulan yang telah disebutkan, teknologi membran ini semakin canggih, efisien, efektif, selektif, biaya.

kapital, operasi dan pemeliharaan sistem terus makin ditekan, murah, kompetitif dibanding cara-cara tradisional konvensional yang setara (Hartono, 1997).

\section{METODOLOGI PENELITIAN}

Pada percobaan ini filter keramik yang digunakan yaitu Membran keramik buatan dan Membran keramik pabrikasi.

Adapun lokasi-lokasi yang digunakan sebagai tempat penelitian ini adalah : Lokasi pengambilan sampel air baku bertempat di Sungai Musi. Penelitian ini adalah skala laboratorium yang dilaksanakan di laboratorium Teknik Pemisahan Jurusan Teknik Kimia Fakultas Teknik Universitas Sriwijaya. Analisa sampel untuk parameter limbah cair awal dan akhir dilakukan di Laboratorium Kualitas Air, Badan Riset dan Standardisasi Nasional Provinsi Sumatera Selatan. 
Alat dan bahan utama yang digunakan adalah : Membran keramik buatan, Membran keramik Pabrikasi, Flow meter, Selang plastik, Pressure gauge, Pipa PVC, Pompa, pH meter, TDS meter, Gelas ukur dan gelas erlenmeyer, AAS, Tabung reaksi, air Sungai Musi.

\section{Skema Peralatan}

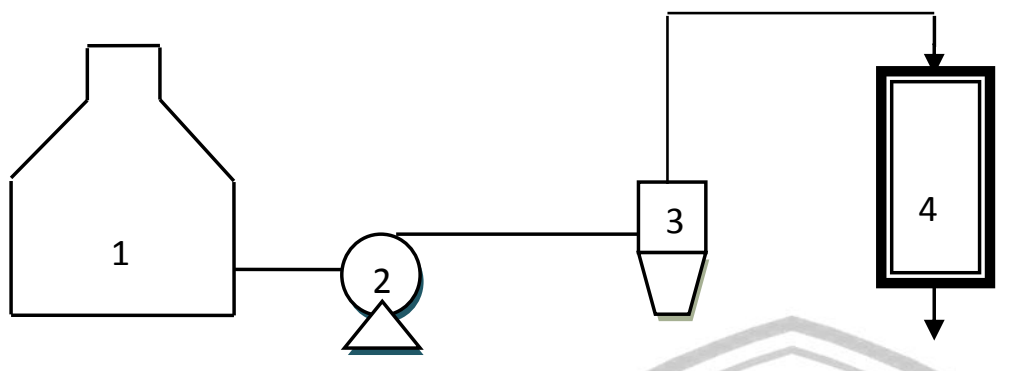

\section{Gambar 1 : Rangkaian Alat Penelitian Non Koagulan}
Keterangan: 1. Tangki Air,
3. Flowmeter umpan
4. Membran Keramik

Pengambilan data dari sampel permeate dilakukan setiap 15, 30, 45 dan 60 menit. Parameter yang dianalisa meliputi fluks, $\mathrm{pH}$, kekeruhan dan TDS.

\section{HASIL DAN PEMBAHASAN}

Salah satu parameter untuk melihat kinerja dari membran adalah fluks yang merupakan ukuran kecepatan suatu spesi melewati membran persatuan luas dan waktu dengan gradient tekanan sebagai gaya dorong. Fluks umunya dirumuskan sebagai berikut :

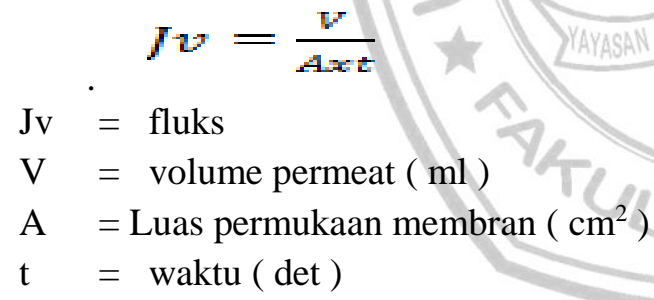

Pada penelitian ini volume permeat yang dihasilkan pada tekanan 32 dan 36 psi dengan variasi waktu (15, 30, 45 dan 60 menit) diamati, sehingga nilai fluks dapat diketahui melalui perhitungan menggunakan persamaan untuk fluks. Tabel dan grafik dibawah ini menggambarkan pengaruh jenis membran terhadap fluks.

Tabel 2. Fluks permeate pada tekanan 32 psi

\begin{tabular}{|c|c|c|c|}
\hline $\begin{array}{c}\text { Jenis } \\
\text { Membran }\end{array}$ & $\begin{array}{c}\text { Waktu } \\
(\text { menit })\end{array}$ & $\begin{array}{c}\text { Volume } \\
(\mathrm{L})\end{array}$ & $\begin{array}{c}\text { Fluks } \\
\left(\mathrm{L} / \mathrm{m}^{2} \text {.jam }\right)\end{array}$ \\
\hline \multirow{2}{*}{$\begin{array}{c}\text { Membran } \\
\text { Keramik } \\
\text { Buatan }\end{array}$} & 15 & 25,90 & 2399,54 \\
\cline { 2 - 4 } & 30 & 26,20 & 1213,67 \\
\cline { 2 - 4 } & 45 & 26,10 & 806,02 \\
\hline \multirow{2}{*}{$\begin{array}{c}\text { Membran } \\
\text { Keramik } \\
\text { Komersial }\end{array}$} & 60 & 23,50 & 544,30 \\
\cline { 2 - 4 } & 30 & 22,40 & 1506,95 \\
\cline { 2 - 4 } & 45 & 22,28 & 716,44 \\
\cline { 2 - 4 } & 60 & 22,10 & 352,79 \\
\hline
\end{tabular}




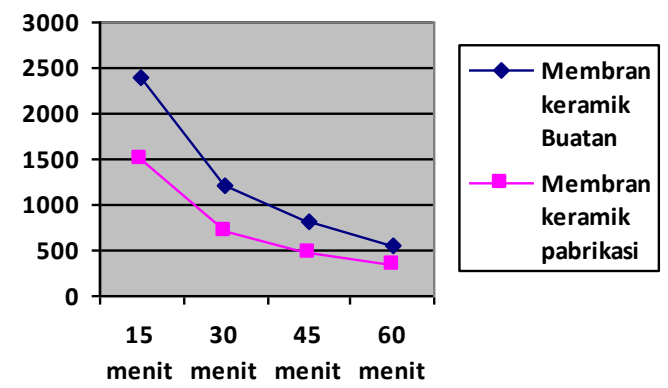

Gambar 2. Pengaruh jenis membran terhadap fluks pada tekanan 32 psi

Tabel 3. Fluks permeate pada tekanan 36 psi

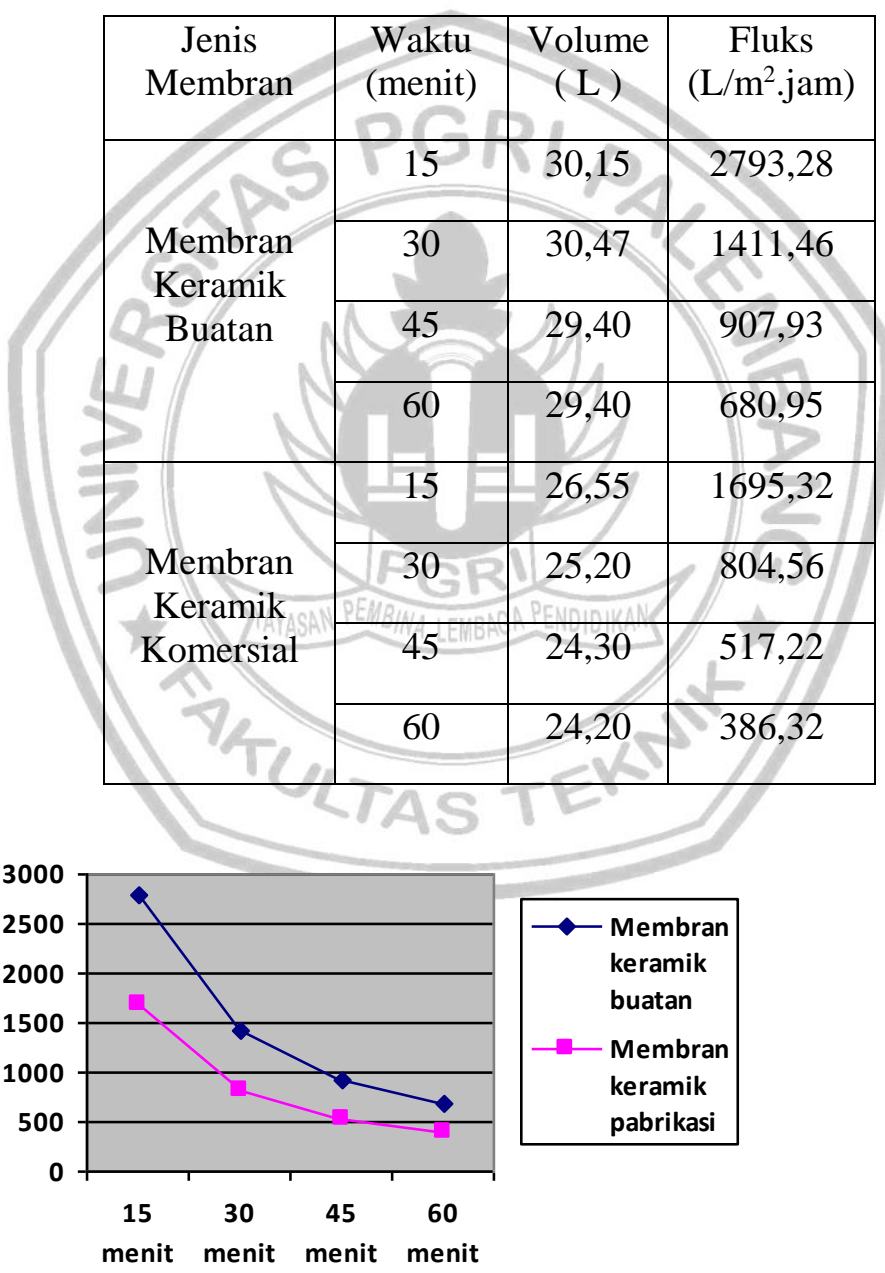

Gambar 3. Pengaruh jenis membran terhadap fluks pada tekanan 36 psi

Dari grafik fluks di atas terlihat bahwa nilai fluks permeate pada membran keramik buatan lebih besar dibandingkan fluks permete pada membran keramik pabrikasi. Fluks pada tekanan 36 psi lebih baik dibandingkan pada tekanan 32 psi.

Secara umum terjadi penurunan fluks pada tiap membran keramik yang berarti bahwa adanya penurunan kinerja membran. Hal ini bisa diakibatkan adanya fouling sepanjang proses operasi filtrasi 
air baku, diantaranya akibat pengendapan dari padatan yang mungkin masih terlarut dalam air baku dan lolos pada permukaan membran sehingga menutup sebagian pori-pori membran.

\section{KESIMPULAN}

1. Pada penelitian ini fluks lebih besar didapat pada filtrasi yang menggunakan membran keramik buatan dibandingkan membran keramik pabrikasi .

2. Filtrasi pada tekanan 36 psi lebih baik nilai fluksnya dibandingkan pada tekanan $32 \mathrm{psi}$.

\section{DAFTAR PUSTAKA}

Hartono, A.J, (1997). Teknologi Membran Pemurnian Air. Edisi 1. Yogyakarta.

Sutrisno, (2004). Dasar-Dasar Pengelolaan Air Limbah. Jakarta. Universitas Indonesia Press

-(2016). Peraturan Gubernur Sumatera Selatan No 18 tahun 2016 tentang Baku Mutu Limbah Cair (BMLC) bagi Kegiatan Industri, Hotel, Rumah Sakit, Domestik dan Pertambangan.

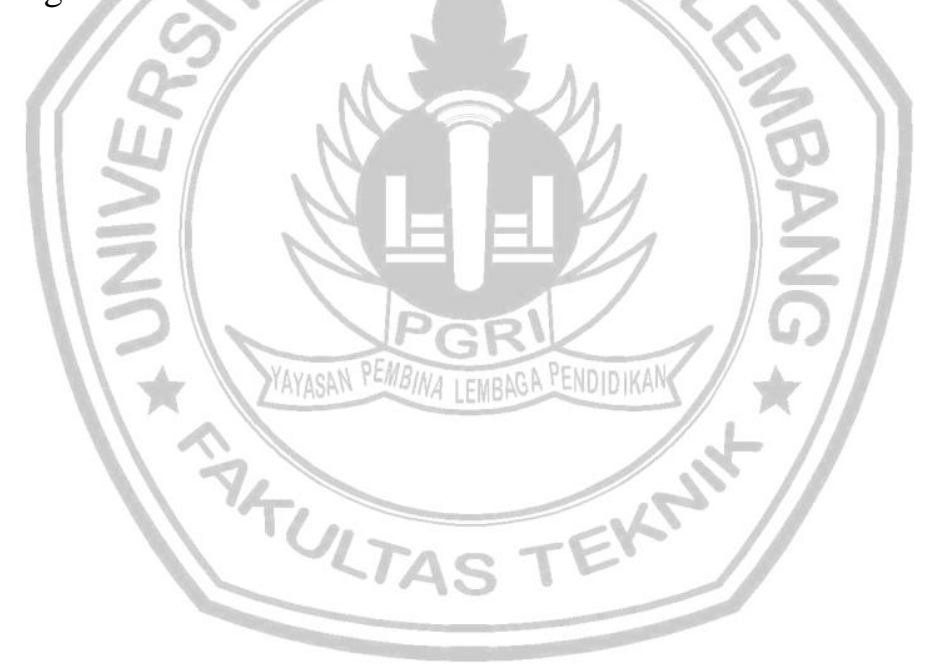

